\title{
Preferences and Perceived Value of WIC Foods Among
}

\section{WIC Caregivers}

\author{
Summer Weber, $\mathrm{PhD}, \mathrm{RD}^{1}$; Keriann Uesugi, $\mathrm{PhD}, \mathrm{MPH}^{2}$; Haley Greene, $\mathrm{BS}^{1}$; \\ Stephanie Bess, MS, $\mathrm{RD}^{3}$; LaShon Reese, MEd, RD, LDN ${ }^{3}$; Angela Odoms-Young, $\mathrm{PhD}^{2}$
}

\begin{abstract}
Objective: To evaluate preferences for and values of Special Supplemental Nutrition Program for Women, Infants, and Children (WIC) foods and packages and understand what factors may influence these preferences and values.

Design: Using a mixed-methods approach, surveys and individual in-depth interviews were conducted to measure and understand preferences for specific WIC foods and how much WIC food packages are worth to participants.

Setting: Eight WIC clinics across Illinois.

Participants: Caregivers of infants enrolled in WIC for at least 3-6 months.

Phenomenon of Interest: : Preferences for WIC foods, WIC food package values, and factors that influence these categories.

Analysis: Frequencies were gathered to analyze survey data and interview transcripts were analyzed using constant comparative analysis to identify emergent themes.

Results: Survey $(n=150)$ and interview $(n=31)$ participants valued the food packages in WIC but they valued the infant packages more. The cash value fruit and vegetable voucher increased the perceived value of the program for many participants. Restrictions on food choice preferences (eg, type of milk) detracted value from the program.

Conclusions and Implications: This study shows that providing more choice in the program could improve satisfaction with WIC overall. More research is warranted with a more representative sample to assess whether expanded food choice would improve value of and preference for WIC foods.
\end{abstract}

Keywords: food preferences, low income, retention, WIC (J Nutr Educ Behav. 2018; 50:695-704.)

Accepted April 29, 2018.

\section{INTRODUCTION}

The mission of the Special Supplemental Nutrition Program for Women, Infants, and Children (WIC) is

to safeguard the health of lowincome women, infants, and children up to age 5 who are at nutrition risk by providing nutritious foods to supplement diets, information on healthy eating, and referrals to health care. ${ }^{1}$
Eight million participants are served by WIC each month ${ }^{1}$ and the positive impact on maternal and child health outcomes has been long documented. Participation in WIC has been associated with better-quality diets, ${ }^{2}$ obesity reduction among children, ${ }^{3}$ and decreased risk for food insecurity in households with children. ${ }^{4}$ Nevertheless, despite the positive impact of the program, a growing number of WIC participants discontinue participation before the

\footnotetext{
${ }^{1}$ Division of Epidemiology, Department of Medicine, Vanderbilt University Medical Center, Nashville, TN

${ }^{2}$ Department of Kinesiology and Nutrition, University of Illinois Chicago, Chicago, IL

${ }^{3}$ Illinois Special Supplemental Nutrition Program for Women, Infants, and Children, Springfield, IL Conflict of Interest Disclosure: The authors have not stated any conflicts of interest.

Address for correspondence: Summer Weber, PhD, RD, Division of Epidemiology, Department of Medicine, Vanderbilt University Medical Center, 2525 West End Ave, Nashville, TN 37203; Phone: (615) 875-6193; E-mail: summer.weber@vumc.org

(c) 2018 Society for Nutrition Education and Behavior. Published by Elsevier Inc. All rights reserved.

http://doi.org/10.1016/j.jneb.2018.04.280
}

end of eligibility. Children aged 1-4 years comprise the largest eligible participant group but hold the lowest coverage rate; only $49.8 \%$ of eligible children participated in 2013 whereas coverage rates for infants (birth to 11 months), pregnant women, and postpartum women were $84.4 \%, 68.4 \%$, and $77.8 \%$, respectively. ${ }^{5}$ Previous studies suggested that the perceived value of WIC food packages may have a role in participants' intention to stay enrolled in the program. For example, in a survey of WIC participation patterns, approximately $26 \%$ of those who prematurely exited the program indicated that it was too much effort and the benefits were not worth the time. $^{6}$ In addition, limited variety, availability, and quantity of foods have been reported to be major barriers to using WIC services. ${ }^{7}$ Given differences in coverage among participant groups, intention to remain in the program may vary at different 
stages owing to the perceived and actual value of the packages. However, the specific foods available to participants in WIC and the perceived value attached to them remain largely unexplored. The purposes of this study were to assess participants' preferences for and perceived value of WIC foods and packages and to gain a deeper understanding of the factors that may shape these preferences and values. Understanding WIC food preferences and food behavior in participants' own words using a qualitative approach, supplemented by quantitative data, could help policy makers improve WIC and inform efforts to keep families enrolled.

\section{METHODS}

\section{Study Design}

This study builds on a larger evaluation of the pilot WIC to 5 program. WIC to 5 was an intervention study to increase WIC participation and retention among eligible children in Illinois. Based partly on constructs from the Theory of Planned Behavior, WIC to 5 included activities to improve client awareness of WIC benefits, improve staff-client interactions, and improve image and understanding of WIC among health care providers. Four clinic sites were selected to participate in the WIC to 5 intervention to reflect both rural and urban counties within the state and various WIC agency structures (eg, county health department, health system). These 4 sites were then matched to 4 comparison sites for demographics, agency structure, caseload, and urbanicity for a total of 8 clinic sites. This study's analysis included 2 data sources: (1) a baseline survey of 150 parents and caregivers of WIC children, as well as (2) an indepth interview conducted with a subsample $(\mathrm{n}=31)$ from April, 2015 to July, 2016. This project was approved by the University of Illinois Chicago Institutional Review Board via expedited review.

\section{Participant Recruitment and Eligibility}

Participants aged $\geq 16$ years with children aged 3-6 months who were enrolled in WIC were eligible for the study at baseline. Because WIC participation rates decline as children age, the larger retention study aimed to recruit parents and caregivers before their child reached age 7 months, when they were more likely to leave the program. ${ }^{6}$ Participants were recruited using passive and active strategies including direct contact, flyers, and an introduction to the study at nutrition education classes. All data collectors recruited participants in compliance with Federal Human Subjects Regulations, and eligible parents and caregivers completed informed consent.

From the group recruited at baseline, a subsample of participants was recruited by phone to participate in an in-depth interview about WIC foods. To obtain a sample with diverse characteristics, maximum variation sampling ${ }^{8}$ was used for the in-depth interviews. The participants were selected based on their potential to provide data that were rich in information and to offer useful manifestations of the phenomenon of interest. Sampling was therefore aimed at the research question, not empirical simplification. ${ }^{8}$ Theoretical sampling continued and was repeated until the data analysis reached saturation. This sampling method was employed to garner information from interview participants that varied by ethnicity, age, socioeconomic status, household composition, employment status, formula use, breastfeeding status, and WIC experience. Saturation was determined to be reached when themes about food choice and WIC food preferences were no longer unique.

\section{Data Collection}

Survey measures. A WIC food preferences questionnaire was developed to measure the perceived value of foods available in the different WIC food packages. Participants were asked to rank on a 5-point Likert scale their preferences for receiving each WIC food, in which $1=$ very much dislike and $5=$ very much like.

Participants were also given a value-oriented questionnaire at baseline. This questionnaire asked them to reflect on the monthly cost in dollars of each WIC food package at different stages throughout participation and whether it was worth the time and effort to stay in WIC at each stage. These measures were developed with each type of WIC food and WIC food package in mind and were based on results from formative qualitative interviews on the barriers and facilitators to WIC retention. ${ }^{9}$ The measures went through expert review with WIC staff at each site as well as state and regional coordinators.

In-depth interviews. Guided by a constructivist approach, interviews lasted approximately 1 hour and were conducted in a private area within the clinic or in the participant's home by a dietitian trained in qualitative methodology and public health nutrition. Constructivist inquiry provides an opportunity to gain a more detailed understanding of multilevel processes by allowing participants to report their own views, not limiting them solely to the researcher's conceptualization of the issues. ${ }^{10}$ Interviews were conducted with several open-ended research questions in the form of a semistructured interview protocol informed by formative research on the barriers and facilitators to using WIC services. ${ }^{7,9}$ The interview protocol was also based on previous qualitative research with dimensions related to food choice, and was edited to include motivations and values behind eating behavior. ${ }^{11} \mathrm{~A}$ panel of 5 doctoral-level experts in public health nutrition as well as state and regional WIC coordinators reviewed the interview protocol.

\section{Data Analysis}

Survey analysis. The researchers calculated descriptive statistics (including frequencies, means, and range) for participant demographics, WIC food preferences, and perceived value using SPSS Statistics for Windows (version 22.0, IBM Corp, Armonk, NY, 2013). Favorable food ratings (like and very much like) for each WIC food were tabulated. Frequencies were compiled to calculate the percentage of participants who rated each WIC food as favorable (rating of 4 or 5 ) and unfavorable (rating of 1 
or 2). For each WIC food package, the percentage of participants who rated each food package worth $>\$ 100$ was calculated as well as the percentage who did not know the worth of each package. The percentage of participants who agreed that it was worth the time and effort to stay was also calculated for each time point.

Analysis of in-depth interviews. In preparation for data analysis, interview audio files were transcribed verbatim. All transcriptions were reviewed for accuracy by a third party who was familiar with the study population and the WIC program. Before coding, transcripts were read several times to obtain a clearer understanding of issues discussed within each participant's interview. Interview transcripts were then input to a qualitative data management software program to aid in the coding process (version 8, Atlas.ti, Atlas.ti Scientific Software Development GmbH, Berlin, Germany, 2017). Analysis of the interviews was guided by the constant comparative method outlined by Strauss and Corbin. ${ }^{12}$

Transcript text was broken down into smaller conceptual text units that were labeled and coded according to meaning. Code agreement, categories, and themes were finalized with the oversight of an experienced qualitative researcher with expertise in nutrition, the WIC program, and health equity research. A list of codes and code groups was updated and maintained throughout analysis. Codes were queried via key words, like groupings, and other identifiers; then the researchers compared them within and between transcripts. Categories pertaining to those that emerged from the interviews and those anticipated from the literature and semistructured interview protocol were combined according to similar phenomena to develop a final list of categories. The category system was then reviewed and compared with the data many times to determine relationships among constructs and themes. The themes were extracted to examine the relationships among food preferences, perceived value of WIC foods, and retention of child participants in the WIC program.
Intercoder reliability was determined according to procedures by Gough and Conner. ${ }^{13}$ Two additional coders assigned core themes to units of text from all interviews. Allocation of codes was checked to ensure a high level of correspondence between coders $(94 \%$ and $81 \%$, respectively). All 3 coders came together to revise codes and themes according to their meaning until an acceptable consensus was reached (ie, $\geq 95 \%$ of quotations were allocated to the core themes). This was calculated using the joint probability of agreement method described by Thomas et al. ${ }^{14}$

The researchers evaluated trustworthiness and quality of the interview data using the evaluative criteria of Lincoln and Guba, ${ }^{15}$ including prolonged engagement (remaining on-site at WIC clinics throughout the course of this study), persistent observation (staff and client interactions in all areas of the clinic), triangulation of sources (survey questionnaire data), peer debriefing (reports and calls with the WIC state agency and WIC staff as well as presentations of ongoing research at professional conferences), dependability audits (observations of participant interviews by graduate-level students who validated the data collection process and analysis findings), as well as negative case analysis. $^{8}$

\section{RESULTS}

\section{Participant Sample Characteristics}

The characteristics of the larger sample and subsample can be viewed in Table 1.

The proportion of subsample participants' sex, race, ethnicity, education, and employment reflected that of the larger study. Racial demographics for the larger study reflected those of the targeted Illinois WIC sites' caseload information as of October, 2013. However, ethnicity demographics did not reflect the target population because at the time of data collection, a limited number of Hispanic participants $(n=5)$ had been recruited, representing only $3 \%$ of the survey sample.

Although most interview participants $(\mathrm{n}=28)$ had $1-3$ children, 1 had 4,1 had 5 , and 1 had 7. Participants with $>1$ child $(n=17)$ had other children previously enrolled in WIC. Length of enrollment among other children varied; some participants had children who remained enrolled until age 5 years $(n=10)$, some exited the program prematurely at different ages $(\mathrm{n}=4)$, whereas others had mixed experiences with each child $(n=3)$.

\section{Perceived Value of WIC Foods}

Table 2 provides participants' perceived value of the WIC food packages. Over half of the participants $(62 \%)$ estimated the WIC infant package to be worth $>\$ 100$ whereas less than a third of participants thought the WIC women's package during pregnancy and WIC children's package were worth $>\$ 100$. Although almost all participants (93\%) said they knew the worth of the infant food package, fewer of them could say they knew how much the women's and children's packages were worth (19\% and 23\%, respectively). Most agreed it was worth the time and effort to stay in WIC for the packages during infancy (91\%) and pregnancy $(70 \%)$, whereas $36 \%$ of participants said it was worth staying for the children's package.

Results from the qualitative interviews supported the results from the perceived value questionnaires. A contributing factor to the perceived value of the packages for children was the time and effort it took to acquire them:

It's one of those things that you have to weigh the benefits versus your own patience-there are days, like-by the time we got ready to go to the grocery store, I was, like, know what, it's not worth it tonight.-Caregiver, aged 33 years

Participants suggested that it might not be worth it to remain in the program once the child ate real food. Some parents felt they should be able to provide for their child after they no longer needed formula: "The parents should have it all together. You shouldn't really need WIC anymore. They don't need formula" (Caregiver, aged 21 years). 
Table 1. Demographic and Socioeconomic Data of Caregivers of Children Enrolled in WIC Who Were Also Enrolled in WIC to 5 Years of Age

Survey Participants

\section{Characteristic}

Age, y (range [median])

Sex

Male

Female

\section{Race}

Black

White

Asian

Mixed/other

\section{Ethnicity}

Hispanic

\section{Education}

Some high school

High school

General Equivalency Diploma

Some college

Associate's degree

Bachelor's degree

Graduate degree

Refused to answer

Employment

Full-time

Part-time

Not employed

Full-time student

Stay-at-homeparent/homemaker

Refused to answer

Marital status

Married

Separated

Divorced

Single, never married

In relationship, not living with partner

In relationship, living with partner

Infant feeding method

Fully breastfed

Partially breastfed

Formula fed

Supplemental Nutrition Assistance Program recipient

$$
\text { ( } n=150)
$$$$
16-54(25)
$$

$149(99)$

30(97)

$$
\begin{gathered}
88(59) \\
46(31) \\
1(1) \\
15(10)
\end{gathered}
$$

$24(16)$

$47(31)$

$11(1)$

1 (3)

$7(5)$

$2(1)$

$2(7)$

2(1)

$1(3)$

$22(15)$

$6(20)$

$35(23)$

$9(29)$

30 (20)

3 (10)

13 (9)

1 (3)

45 (30)

$12(40)$

5 (3)

31(21)

5 (16)

5 (3)

5 (3)

$52(35)$

3 (10)

7 (23)

20 (13)

6 (19)

29 (19)

8 (26)

19 (13)

9 (29)

15 (10)

115(77)

21 (67)

114 (76)
$26(83)$

WIC indicates Special Supplemental Nutrition Program for Women, Infants, and Children.

Note: Data are $n(\%)$. 
Table 2. Survey Data: Perceived Value of WIC Food Packages Among Caregivers of Children Enrolled in WIC Who Were Also Enrolled in WIC to 5 Years of Age $(n=150)$

\section{Type of WIC Food Packages Participants Were Asked to Evaluate}

\section{Participants Who Think Package Is Worth $>\$ 100 / \mathrm{mo}$}

\section{Participants Who Do Not Know How Much Package Is Worth per Month}

44 (29)

$93(62)$

$45(30)$

29 (19)

$35(23)$
Participants Who Think It Is Worth the Time and Effort to Stay in WIC for Package

105 (70)

$137(91)$

$54(36)$

WIC indicates Special Supplemental Nutrition Program for Women, Infants, and Children. Note: Data are $n(\%)$.

Similar to the survey results, several interview participants reported that they did not know how much the child package was worth and indicated that they were unsure, uninformed, or ambivalent about packages after infancy. Others resented the restrictions they felt were imposed on them, which lowered the perceived value of the package and led to waste:

\section{It's like this: If you're telling peo- ple what they can and can't get all the time, they'll probably get it, but it'll go to waste. Only it's not being used for what it's supposed to be used for, which is the kids and the family, or the breastfeed- ing mother [...] they gonna get it just because it's on the coupon, but it's going to go to waste, or they gonna give it away.-Care- giver, aged 35 years}

\section{Preferences for WIC Foods}

Results from the WIC food preferences questionnaire triangulated with the findings in the in-depth interviews and are displayed in Table 3. Survey participants rated foods in the infant package highly. Infant formula, in particular, was rated favorably by $94 \%$ of all participants. Interviews illustrated that for these families, infant packages were prioritized over other WIC foods and packages owing to the high cost of formula. Participants tended to know exactly how much infant formula would cost if they had to pay retail value:

\footnotetext{
The most important thing is the fact that she gets milk. You know, the baby formula that she needs, because that is very expensive. So,
}

I can just imagine without WIC, we probably wouldn't have food 'cause those little cans of formula almost cost $\$ 18$ a pop.-Caregiver, aged 35 years

Infant cereal and baby foods are provided in WIC infant packages after age 6 months. Overall, survey participants rated foods in the infant package favorably (eg, they liked or very much liked receiving them); however, the interviews indicated that for many parents, these foods were considered a convenient but less nutritious option: "I didn't even give her those cereals because, I mean, it's just calories that fill them up with no nutritional value. So, you know, like, cereal went to waste for me" (Caregiver, aged 32 years).

Some parents preferred to make their own baby food and described the desire to feed their children foods they were eating themselves. Every participant preferred an expanded fruit and vegetable voucher over receiving jarred baby food when asked during the in-depth interview. Participants described infant cereal and baby food going unused, and that it would be more useful if given earlier in the infant's life, before the child reached the point in development at which he or she became more independent in feeding and wanted to hold and touch the food. Many participants followed their own intuition or recommendations from health care providers about readiness for solids:

I think it could have been nice to get baby food earlier, you know, 'cause I started it when he was right at 5 months, because my doctor said anytime between 4 and 6 months is okay. He said when he really starts watching you eat, that's when it's time. And he really started watching me eat, and so, um, yeah, I felt like it was time. So, if they could havemaybe move it up even a month, you know, I think it would be helpful.-Caregiver, aged 31 years

Several interview participants spoke about using infant cereal to thicken the liquid in the bottles to keep their children full and content; 1 participant mentioned that this practice helped her keep her child asleep through the night.

Cash value vouchers (CVVs) from WIC allow families to choose the type of produce they want. Survey participants valued getting fresh fruits and vegetables in their WIC food packages the most; this was reflected in the in-depth interviews. Participants enjoyed selecting their own fruits and vegetables, and many spoke about strategies to expand CVV value by shopping in-season or using it solely toward the household fruit budget because "fruit is more expensive" (Caregiver, aged 32 years). This value was compounded for respondents and their children who said that they especially liked fruits and vegetables. Participants who had older children (enrolled in WIC before 2009) could recall when there were no CVVs in WIC and how much better the program had become:

The fact that they added vegetables and fruit was a good thing. I love that. That was good, 'cause vegetables and fruit are expensive, especially when you're trying to get the more fresher kind.-Caregiver, aged 35 years. 
Table 3. Favorability Ratings for Specific WIC Foods Among Caregivers of Children Enrolled in WIC to 5 Years of Age $(n=150)$

\begin{tabular}{|lcc|}
\hline WIC Food & Favorable (\%) $^{\text {a }}$ & Unfavorable (\%) $^{\mathbf{b}}$ \\
\hline Infant formula & 94 & 4 \\
\hline Baby food & 95 & 5 \\
\hline Infant cereal & 92 & 3 \\
\hline $100 \%$ juice & 93 & 1 \\
\hline Fresh F\&V & 99 & $<1$ \\
\hline Frozen F\&V & 88 & 3 \\
\hline Canned F\&V & 81 & 5 \\
\hline Whole-wheat bread & 83 & 10 \\
\hline Tortillas & 68 & 17 \\
\hline Whole-wheat pasta & 63 & 22 \\
\hline Brown rice & 59 & 23 \\
\hline Oatmeal & 86 & 6 \\
\hline Breakfast cereal & 91 & 5 \\
\hline Peanut butter & 89 & 5 \\
\hline Beans & 70 & 13 \\
\hline Eggs & 97 & 1 \\
\hline Whole milk & 87 & 7 \\
\hline Skim/1\% milk & 49 & 33 \\
\hline Cheese & 93 & 2 \\
\hline
\end{tabular}

F\&V indicates fruits and vegetables; WIC, Special Supplemental Nutrition Program for Women, Infants, and Children.

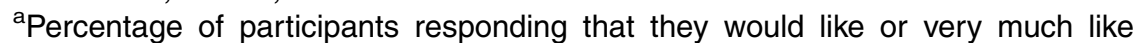
receiving that food from WIC.

${ }^{\mathrm{b}}$ Percentage of participants responding that they would dislike or very much dislike receiving that food from WIC.

Survey participants favored receiving frozen and canned fruits and vegetables slightly less than they did fresh; however, the interview data added another level to these findings. Interview participants stated that frozen and canned varieties saved them time and lasted longer than did fresh, which added value:

I do like the frozen steam-fresh veggies. I do get a lot of those 'cause by the time I get home from work, it's almost 7 , so I have to eat fast, 'cause then it's time for him to get a bath and go to bed. I do buy a lot of fresh produce, but with the freezing stuff-sometimes that does it. I mean, it's not as good for you, but it is easier to just pull something out of the freezer and put something in the microwave than just to sit and make a dinner for an hour.-Caregiver, aged 31 years
I much prefer my canned [vegetables]. So, I have a lot more readymade, easier to make for myself-Caregiver, aged 27 years

Most participants appreciated a choice of grain in the program. Among survey participants, preferences for whole-grain items varied; brown rice was among the most unfavorable foods $(23 \%)$. However, results from qualitative interviews indicated that if 1 type of grain was disliked in the household, most families were content with a different option available in WIC. If participants had issues with grain choices in WIC, interview results revealed that this was because it was not the type of food to which they were accustomed to eating. For example, if participants were used to eating white bread or white rice, the grain options were less valuable to them:

We don't do wheat bread here at the house. We do the white bread. Sometimes I just don't grab it. I prefer to not grab it than for it to come home and nobody eats it and just throw it away or just goes to waste.-Caregiver, aged 25 years

Conversely, if a participant had been raised on healthier whole-grain foods and knew how to cook with them, the choices in WIC were valuable and useful to the household. One participant commented on the importance of choice and suggested additional culturally appropriate options not provided in WIC:

People that's trying to make WIC actually work for them deserve to get an option of certain things. They could be the same [type of] things like wheat bread or oatmeal-you know, grits is a good food for a lot of African Americans-like to eat, you know-they grew up on.-Caregiver, aged 35 years

Breakfast cereal value was variable among participants. Similar to the opinions about whole-grain choices in WIC, some participants thought that the breakfast cereal options were bland, too healthy, not sweet enough, and restrictive. Whereas some participants considered the breakfast cereals in WIC to be too healthy, others did not believe they were healthy enough, citing certain sweetened cereals allowed in WIC such as frosted shredded wheat.

Eggs were a highly favorable food among survey participants (97\%). The interviews supported this finding; however, several participants mentioned that they wished WIC offered more than 1 dozen eggs per child per month. WIC also offered the choice between peanut butter and beans in the women's and children's packages. Participants tended to favor peanut butter slightly over beans in WIC and found it useful; however, it was not a high-priority food for many, and interviewees mentioned that peanut butter would accumulate in their households 
because it was not used at the rate it was provided. Some participants voiced that WIC was restrictive when it came to the type of peanut butter. Participants were also confused as to why peanut butter was offered in WIC when they were informed that young children should not have peanut butter owing to allergy or choking risk. Beans were also valued more when participants knew how to cook with them. Alternatively, many WIC participants were not accustomed to cooking beans and perceived the process of soaking and cooking dry beans to be too much.

Juice was a popular item among participants; survey participants strongly favored receiving it from WIC. Some interview participants were aware of the high sugar content of juice and wondered why an unhealthy item was available in WIC: "WIC is always trying to tell us about rotten teeth and giving them sweets, but then they give him a big juice thing. So, I look at it as just kind of backward" (Caregiver, aged 21 years).

The Special Supplemental Nutrition Program for Women, Infants, and Children offers whole milk to children at age 1 year. Once the child turns 2 years old, skim or low-fat 1\% milk is allowed in the child's package. Less than half of survey participants $(49 \%)$ rated skim or $1 \%$ milk favorably and $33 \%$ rated skim or $1 \%$ milk unfavorably, which made skim or $1 \%$ milk the most unfavorable WIC food item among survey participants. Milk preferences were a major theme mentioned among interviewees. Participants mentioned that they would prefer to have a choice about the type of milk they received and most participants said that they would prefer $2 \%$ or whole milk. Participants reported donating, giving away, or not redeeming vouchers for low-fat or skim milk:

I donate the skim milk or I just don't pick it up. Most of the time, I buy a half-gallon of whole milk because we don't drink the skim or the 1\%. I'm sorry, but who really drinks skim milk or 1\%, you know?-Caregiver, aged 32 years

One participant mentioned disliking skim milk, but it became a

vehicle for added sugar in her and her child's diet, because she reported being able to use it if she mixed it with flavored milk powder or served it with cookies. Furthermore, several participants were aware, or learned from WIC itself, that their 1-year-old children needed the fat in whole milk for brain development. Some participants were then perplexed when their older children were switched to skim milk and were not given an adequate explanation. Participants were told that lower-fat milk was healthier, but this seemed contradictory or unsatisfactory. Some participants and their children did not consume much milk, and 1 participant in particular stated that she did not want her daughter to consume dairy once she was age 1 year. She was disturbed by the thought of anyone giving her daughter cow's milk. These factors regarding milk preference influenced the perceived value of the food packages and WIC in general.

In-depth interview responses showed that WIC foods were less valuable to those who reported picky eating, preferred sweeter tastes, and ate unhealthfully in general. Caregivers who identified themselves as picky eaters when it came to eating vegetables also tended to be those who preferred sweeter cereals and juice in WIC. These caregivers also identified their own tendencies to eat less nutrient-dense food and to make unhealthy choices; for them, the value of the program tended to be lower. Some even mentioned leaving the program:

\begin{abstract}
I left WIC because my son had become kind of picky with his food, and the WIC was just not cutting it with what he wanted. I just finally said, I'll just take him off of it and just worry about my food stamps. [WIC] just didn't provide what I needed at that time. So, it was just, it wasn't worth it at that point.-Caregiver, aged 37 years
\end{abstract}

\section{DISCUSSION}

Participants reported valuing the WIC package(s) they received during their child's infancy more than other packages in WIC. Results from the qualitative interviews indicated that the perceived value of the infant package was influenced by the high cost of formula. An economic analysis of formula and breastfeeding in the WIC program revealed that the retail price of infant formula increased the value of these packages for the first 6 months of the child's life. $^{16}$

Survey participants reported that they liked to receive baby food and infant cereal in the infant package, but interviews revealed that it often came too late in the child's life. Other studies showed similar results and revealed that intakes of infant cereals were similar, regardless of WIC status. ${ }^{17,18}$ Currently, the American Academy of Pediatrics recommends introducing solid foods around age 6 months, but it recognizes that "a substantial number of families introduce complementary solid foods around 3-4 months." ${ }^{19}$ When asked whether they would prefer baby food or a cost-neutral expanded fruit and vegetable voucher, every participant in this study stated that she preferred the latter. These findings were demonstrated in a previous study ${ }^{20}$ about mothers' preferences for fresh fruits and vegetables over baby food fruits and vegetables, in which two thirds of mothers of WIC infants stated that they also preferred CVVs for fruits and vegetables to baby food.

This study demonstrated that the type of milk choice influenced the perceived value of WIC food packages; however, previous studies on satisfaction with the 2009 WIC package changes revealed mixed results. A phone interview survey study with 2,996 WIC participants in California showed overall satisfaction with the package changes and the amounts of foods provided in the packages; however, participants were not asked about their satisfaction with whole or $2 \%$ milk restrictions, only whether they were satisfied with low-fat milk and the amount of low-fat milk provided. Also, participants of children aged $1-2$ years who would have been receiving whole milk were excluded from this study's results. ${ }^{21}$ Another study that included participants' perceptions found that most women and children consumed milk every 
day; of those, more than half of women and $70 \%$ of children reported consuming whole milk. This crosssectional study, including interviews and focus groups with WIC participants in Maryland, revealed that many women in the study did not want to switch to low-fat or skim milk. ${ }^{22}$ Despite participant preferences, WIC remains restrictive when it comes to dairy options for women and children aged $>2$ years. The content of WIC food packages for women and children reflects recommendations set forth by the Dietary Guidelines for Americans, which recommend low-fat dairy choices $^{23}$ despite recent and growing evidence that full-fat dairy does not adversely impact health or weight ${ }^{24-27}$ and may improve it. ${ }^{26,28}$

In the current study, some participants made skim milk from WIC more acceptable by adding sugar to it (eg, flavored syrup or powder, or by serving it with cookies). A recent review of the literature on high-sugar additions to milk and its effects on child health revealed mixed results ${ }^{29}$ and emphasized that children who drank flavored milk consumed more milk than did children who drank plain milk; however, overall micronutrient intake was similar regardless of the type of milk consumed. ${ }^{29}$ Regarding weight status, flavored milk consumption had little effect on normal-weight children; however, more research is needed on its effects in overweight or obese children. ${ }^{29}$ The review also found that most children rated flavored milk as highly palatable. $^{29}$

Participants in this study enjoyed juice provided in WIC; however, many were aware of the adverse consequences it had on their children's overall health and dental health. ${ }^{30}$ Considering this and other evidence tying juice to childhood overweight and obesity, ${ }^{31,32}$ a recent viewpoint published by the Journal of the American Medical Association Pediatrics called for the removal of juice in WIC, with a reallocation of funds toward fruits and vegetables. ${ }^{33}$ The Dietary Guidelines for Americans acknowledge that young children should consume no more than 4-6 fl oz/d of $100 \%$ fruit juice because it contributes extra calories when it is consumed in excess, ${ }^{23}$ which is the case for many WIC children. ${ }^{18}$ Moreover, WIC has removed juice from infant packages and reduced it in women's and children's packages; however, data from the Feeding Infants and Toddlers Study revealed that children in WIC consumed more $100 \%$ juice, fruit-flavored drinks, and sweetened beverages than did nonparticipants. ${ }^{18}$ A previous study showed that although they were satisfied with the juice provided in WIC, participants were also satisfied in general with the decrease in the amount of juice provided in the women's and children's packages. $^{21}$

Participants repeated the desire for choice in the WIC program, and where choice was offered, the program was valued. Cash value vouchers for fruits and vegetables have addressed the desire for autonomy in food choice in at least 1 WIC food category; participants in other studies also reported that purchasing food items with CVVs made the WIC experience worth the effort each month. ${ }^{34}$ Other studies showed similar results regarding satisfaction with fruits and vegetables provided in the program after the 2009 package change, ${ }^{20,21}$ as well as with preferences for fresh fruits and vegetables, while valuing canned and frozen varieties for convenience and cost. ${ }^{22}$ Before CVVs were introduced to the WIC food packages in 2009, a study on the dietary patterns and feeding practices of children participating in WIC revealed that WIC participants' and eligible nonparticipants' fruit and vegetable consumption was low and the most popular vegetable for both WIC and non-WIC toddlers was potatoes. $^{18}$

Participants in this study favored peanut butter over beans; however, the interview results revealed that participants who were familiar with cooking beans favored beans more did than those who were not accustomed to cooking or eating beans. These results were similar to the findings in the Maryland Food Preference Study, in which non-Hispanic participants preferred peanut butter over beans. Hispanic participants in the survey study also reported that they (44\%) and their children (57\%) would consume more beans if provided by WIC. ${ }^{22}$ This finding aligned with Hispanic interview participants' preferences in the current study; however, only 2 Hispanic participants were interviewed.

This novel study explored the preferences and perceptions of WIC caregivers through both survey data and qualitative in-depth interviews. Nevertheless, this study had limitations. There was limited representation of Hispanic families in the sample and food preference data gathered in Illinois, and thus the study may not be generalizable to WIC participants in other states or at the national level. There was also a lack of pilot testing with the subject population for both surveys and interview questions. This study included only baseline survey data that were captured during the time when the in-depth interviews were completed. Longitudinal quantitative results about participants' preferences and perceived value may have varied over time; however, participants' own words from the in-depth interviews triangulated with the baseline data remain important in informing future interventions and policy aimed at improving WIC.

\section{IMPLICATIONS FOR RESEARCH AND PRACTICE}

Overall, choice was appreciated in several categories in this study; however, many participants still felt strongly about the restrictions in WIC. Expanding choices and autonomy in WIC has improved participant health outcomes, ${ }^{3,35}$ and giving more choice such as those provided by CVVs for fruits and vegetables could improve satisfaction with the program overall. ${ }^{2,22}$ Findings from this study inform a timely need because practitioners and WIC families rely on recommendations to improve future revision cycles of WIC food packages. If other food category choices are expanded, namely for unrestricted types of milk in the packages for women and children, WIC may be able to retain more families in the program after the child turns age 1 year and reduce program benefits from going to waste. More 
research is warranted with a more representative sample to assess whether expanding food choice could improve participation in WIC and redemption of benefits.

\section{ACKNOWLEDGMENTS}

This project was funded by the State of Illinois through a grant from the US Department of Agriculture.

\section{SUPPLEMENTARY DATA}

Supplementary data related to this article can be found at https://doi. org/10.1016/j.jneb.2018.04.280.

\section{REFERENCES}

1. Oliveira V, Frazao E. The WIC program: Background, trends, and economic issues, 2015 edition https:// www.ers.usda.gov/publications/pubdetails/?pubid=43927. Accessed March 12, 2017.

2. Whaley SE, Ritchie LD, Spector P, Gomez J. Revised WIC food package improves diets of WIC families. J Nutr Educ Behav. 2012;44:204-209.

3. Chiasson MA, Findley SE, Sekhobo JP, et al. Changing WIC changes what children eat. Obesity (Silver Spring). 2013;21:1423-1429.

4. Metallinos-Katsaras E, Gorman KS, Wilde P, Kallio J. A longitudinal study of WIC participation on household food insecurity. Matern Child Health J. 2011;15:627-633.

5. Johnson P, Huber E, Giannarelli L, Betson D. National and state-level estimates of special supplemental nutrition program for women, infants, and children (WIC) eligibles and program reach, 2013 https://fns-prod.azureedge.net/sites/ default/files/ops/WICEligibles2013Volume1.pdf. Accessed March 12, 2017.

6. Jacknowitz A, Tiehen L. US Department of Agriculture. WIC participation patterns: An investigation of delayed entry and early exit. https://permanent. access.gpo.gov/websites/www.ers.usda. gov/media/134411/err109.pdf. Accessed March 12, 2017.

7. Woelfel ML, Abusabha R, Pruzek R, Stratton H, Chen SG, Edmunds LS. Barriers to the use of WIC services. $J$ Am Diet Assoc. 2004;104:736-743.
8. Patton MQ. Qualitative Research and Evaluation Methods. 3rd ed. Thousand Oaks, CA: Sage; 2002.

9. US Department of Agriculture Food and Nutrition Service. Summary of WIC state agency strategies for increasing child retention. https://wicworks. fns.usda.gov/sites/default/files/ uploads/ChildRetentionStrategiesReport. pdf. Accessed March 12, 2017.

10. Schwandt TA. Constructivist, interpretive approaches to human inquiry. In: Denzin NK, Lincoln YS, editors. Handbook of Qualitative Research. Thousand Oaks, CA: Sage; 1994. p. 118-137.

11. Devine CM. A life course perspective: understanding food choices in time, social location, and history. J Nutr Educ Behav. 2005;37:121-128.

12. Strauss A, Corbin J. Basics of Qualitative Research: Techniques and Procedures for Developing Grounded Theory. 3rd ed. Thousand Oaks, CA: Sage; 2008.

13. Gough B, Conner MT. Barriers to healthy eating amongst men: a qualitative analysis. Soc Sci Med. 2006;62:387-395.

14. Thomas EL, Puig Ribera A, Senye-Mir A, Eves FF. Promoting healthy choices in workplace cafeterias: a qualitative study. J Nutr Educ Behav. 2016;48:138145.

15. Lincoln Y, Guba E. Naturalistic Inquiry. Newbury Park, CA: Sage Publications; 1985.

16. Drago R. The WIC program: an economic analysis of breastfeeding and infant formula. Breastfeed Med. 2011;6:281-286

17. Ponza M, Devaney B, Ziegler P, Reidy K, Squatrito C. Nutrient intakes and food choices of infants and toddlers participating in WIC. J Am Diet Assoc. 2004;104(1 suppl):s71-s79.

18. Deming DM, Briefel RR, Reidy KC. Infant feeding practices and food consumption patterns of children participating in WIC. J Nutr Educ Behav. 2014;46(3 suppl):S29-S37.

19. American Academy of Pediatrics. Policy on infant food and feeding. https:// www.aap.org/en-us/advocacy-andpolicy/aap-health-initiatives/HALFImplementation-Guide/Age-SpecificContent/pages/infant-food-and-feeding.aspx. Accessed March 12, 2017.

20. Kim LP, Whaley SE, Gradziel PH, Crocker NJ, Ritchie LD, Harrison GG. Mothers prefer fresh fruits and vegetables over jarred baby fruits and vegetables in the new special supplemental nutrition program for women, infants, and children food package. J Nutr Educ Behav. 2013;45:723-727.

21. Ritchie LD, Whaley SE, Crocker NJ. Satisfaction of California WIC participants with food package changes. J Nutr Educ Behav. 2014;46(3 suppl): S71-S78.

22. Black MM, Hurley KM, Oberlander SE, et al. Participants' comments on changes in the revised special supplemental nutrition program for women, infants, and children food packages: the Maryland Food Preference Study. J Am Diet Assoc. 2009;109:116-123.

23. US Department of Health and Human Services and US Department of Agriculture. 2015-2020 Dietary Guidelines for Americans. 8th ed. https://health. gov/dietaryguidelines/2015/resources/ 2015-2020_Dietary_Guidelines.pdf.

Accessed March 12, 2017.

24. Scharf RJ, Demmer RT, DeBoer MD. Longitudinal evaluation of milk type consumed and weight status in preschoolers. Arch Dis Child. 2013;98:335-340.

25. Huh SY, Rifas-Shiman SL, RichEdwards JW, Taveras EM, Gillman MW. Prospective association between milk intake and adiposity in preschoolaged children. J Am Diet Assoc. 2010;110:563-570.

26. Vanderhout SM, Birken CS, Parkin PC, et al. Relation between milk-fat percentage, vitamin $\mathrm{D}$, and BMI z score in early childhood. Am J Clin Nutr. 2016;104:1657-1664

27. O'Connor TM, Yang SJ, Nicklas TA. Beverage intake among preschool children and its effect on weight status. Pediatrics. 2006;118:e1010-e1018.

28. van der Gaag EJ, Forbes K. The immunomodulating effect of a diet consisting of green vegetables, beef, whole milk and full-fat butter for children with non-specific elevated IgE. Int J Vitam Nutr Res. 2014;84:310-319.

29. Fayet-Moore F. Effect of flavored milk vs plain milk on total milk intake and nutrient provision in children. Nutr Rev. 2016;74:1-17.

30. Catteau C, Trentesaux T, Delfosse C, Rousset MM. Consumption of fruit juices and fruit drinks: impact on the health of children and teenagers, the dentist's point of view. Arch Pediatr. 2012;19:118-124.

31. Faith MS, Dennison BA, Edmunds LS, Stratton HH. Fruit juice intake predicts increased adiposity gain in children from low-income families: 
weight status-by-environment interaction. Pediatrics. 2006;118:2066-2075.

32. Wang YC, Bleich SN, Gortmaker SL. Increasing caloric contribution from sugar-sweetened beverages and 100\% fruit juices among US children and adolescents, 1988-2004. Pediatrics. 2008;121: e1604-e1614.

33. Ferris HA, Isganaitis E, Brown F. Time for an end to juice in the special supplemental nutrition program for women, infants, and children. JAMA Pediatr. 2017;171:509-510.

34. Bertmann FM, Barroso C, OhriVachaspati P, Hampl JS, Sell K, Wharton CM. Women, infants, and children cash value voucher (CVV) use in Arizona: a qualitative exploration of barriers and strategies related to fruit and vegetable purchases.
J Nutr Educ Behav. 2014;46(3 suppl): S53-S58.

35. Odoms-Young AM, Kong A, Schiffer LA, et al. Evaluating the initial impact of the revised Special Supplemental Nutrition Program for Women, Infants, and Children (WIC) food packages on dietary intake and home food availability in African-American and Hispanic families. Public Health Nutr. 2014;17:83-93.

\section{Coffee with the JNEB Editors @ SNEB Annual Conference}

Sunday, July 22 • 7:00-8:00 am

Join Editor in Chief Karen Chapman-Novakofski and other editorial staff members from the Journal of Nutrition Education and Behavior (JNEB) for coffee and informal conversation at the SNEB Annual Conference.

We hope to see you there! 